\title{
Adolescent mental health and unemployment over the lifespan: Population evidence from Sweden
}

\author{
Victoria Mousteri $^{\mathrm{a}, *}$, Michael Daly ${ }^{\mathrm{a}, \mathrm{b}, \mathrm{c}}$, Liam Delaney ${ }^{\mathrm{a}, \mathrm{b}}$, Per Tynelius ${ }^{\mathrm{d}, \mathrm{e}}$, Finn Rasmussen ${ }^{\mathrm{d}, 1}$

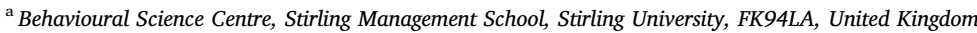 \\ ${ }^{\mathrm{b}}$ UCD Geary Institute, University College Dublin, Belfield, Dublin 4, Ireland \\ ${ }^{c}$ Department of Psychology, Maynooth University, Maynooth, Co. Kildare, Ireland \\ ${ }^{\mathrm{d}}$ Department of Public Health Sciences, Karolinska Institutet, SE-17176, Stockholm, Sweden \\ ${ }^{\mathrm{e}}$ Centre for Epidemiology and Community Medicine, Stockholm County Council, Stockholm, Sweden
}

\section{A R T I C L E I N F O}

\section{Keywords:}

Mental health

Psychiatric conditions

Recession

Unemployment

Siblings fixed-effects

Sibling comparisons

\begin{abstract}
A B S T R A C T
Rationale: Symptoms of mental health problems have been shown to predict adverse labour market outcomes including unemployment, but no studies have used sibling models to examine the relationship between clinically diagnosed psychiatric conditions in adolescence and subsequent unemployment.

Objective: This study used extensive Swedish registry data to investigate the link between psychiatric conditions diagnosed during military conscription and unemployment over two decades. Further, we identified whether this relation was amplified during an economic downturn and tested whether it was affected by adjustment for unobserved family characteristics using sibling fixed-effects models.

Method: Psychiatric conditions were diagnosed by psychologists and psychiatrists at military conscription in sample of 929,191 Swedish men (mean age = 18.4 years) between 1969 and 1989. The average number of days unemployed per year was observed from 1992 to 2012, using the records of the Swedish Public Employment Services.

Results: After adjustment for physical health and childhood socioeconomic status those diagnosed with any psychiatric condition experienced approximately an additional 10 days per year unemployment compared to others. Alcohol (16 days unemployment) and other substance use disorders (17 days) were the strongest predictors of exposure to future unemployment, followed by personality disorders (10 days), neurotic and adjustment conditions (nine days), and depressive disorders (six days). Family background factors accounted for approximately half of the observed relationship between mental health conditions and unemployment. Psychiatric conditions interacted with macroeconomic conditions such that those with pre-existing alcohol-related, and neurotic and adjustment disorders were disproportionately more likely to become unemployed following the 1990s crisis in Sweden.

Conclusions: Adolescent mental health conditions forecast an elevated risk of unemployment, which endures over the life course and is amplified in times of economic uncertainty. Investment in youth mental health services and alcohol and substance use prevention programs may yield economic benefits by reducing unemployment.
\end{abstract}

\section{Introduction}

Decades of research has demonstrated that unemployed individuals are at markedly elevated risk of psychological distress and long-run welfare and wage scarring effects (Clark et al., 2001; Daly and Delaney, 2013; Paul and Moser, 2009; Mousteri et al., 2018). Unemployment also generates pervasive societal costs, including reduced productivity and increased health care service usage and social welfare-related costs. For these reasons, understanding the factors that shape unemployment levels across working life is crucial. Unemployment is typically considered a consequence of prevailing economic conditions such as the sharp decline in consumer demand and economic activity in the aftermath of the recent financial crisis. However, recent evidence suggests that psychological problems may also play a key role in shaping adverse

\footnotetext{
${ }^{*}$ Corresponding author. Behavioural Science Centre, Cottrell Building, Stirling, FK94LA, University of Stirling, United Kingdom.

E-mail address: victoria.mousteri@stir.ac.uk (V. Mousteri).

${ }^{1}$ Retired.
} 
labour market experiences (Layard, 2013) including unemployment, absenteeism, low productivity (Bubonya et al., 2016; Lagerveld et al., 2010; Lerner and Henke, 2008), and reduced earnings (Butterworth et al., 2012; Ettner et al., 1997). In the present study, we aimed to extend existing work by examining the link between adolescent mental health conditions and trajectories of unemployment across life. To do so, we capitalized on data from a sample of almost all Swedish males who underwent a mental health assessment during late adolescence as part of compulsory military service between 1969 and 1989 .

Understanding the potential impact of psychological problems on unemployment is particularly important considering that the economic burden of psychiatric disorders was estimated to be 3.5\% of GDP in European Union in 2010, with benefit expenditure and productivity losses accounting for $50 \%$ of the total cost (Gustavsson et al., 2011; OECD, 2015). Further, in advanced nations it has been suggested that more than one third of sickness and disability caseloads may be due to mental health problems (Layard, 2013). Similarly, in Sweden mental health accounts for $60 \%$ of all sickness-benefits cases and represents a key cause of labour market drop-out (OECD, 2013). Swedish young people appear to be particularly vulnerable, and from 2003 to 2010 experienced a sustained growth in new disability claims due to mental illness that was larger than that of other OECD countries for which data are available (OECD, 2013).

International estimates of the unfavourable effect of mental health on work outcomes are supported by a growing body of empirical work. For example, Ettner et al. (1997) found that suffering from any mental health condition in the last year predicted an 11-percentage point reduction in the probability of being employed among American workers. Subsequent studies have confirmed that being currently diagnosed with any psychiatric condition is linked to a reduced probability of being employed or actively engaged in the labour market (Banerjee et al., 2015; Chatterji et al., 2011). Psychological problems during childhood have also been shown to forecast long-term economic outcomes including sustained reductions in income (Evensen et al., 2017; Goodman et al., 2011) and an elevated probability of unemployment (Egan et al., 2015).

The above studies are notable in that they have taken steps to rule out reverse causality (i.e., the contribution of labour market experiences to mental health) either by incorporating instrumental variables or by drawing on measures of mental health elicited in childhood. Recent studies have also compared the economic outcomes of siblings in order to account for confounding due to unobserved family background and neighbourhood factors (Currie et al., 2010; Delaney and Smith, 2012; Evensen et al., 2017; Lundborg et al., 2014; Smith and Smith, 2010). This comparison is necessary because growing up in economically disadvantaged or otherwise adverse family conditions could detrimentally affect both adolescent mental health and labour market trajectories and explain why these outcomes are interrelated (e.g., Hillis et al., 2004). For example, Fletcher (2013) examined within-family differences in depressive symptoms among U.S. adolescents to show that depressive symptoms predicted an earnings penalty and decrease in the probability of labour force participation at age 30 in a U.S. sample. Lundborg et al. (2014) drew on the same source of Swedish military conscription data as the current study, to show that being diagnosed with a psychiatric disorder in adolescence was associated with reductions in the likelihood of positive earnings and total earnings after controlling for unobserved family background effects.

While it is important to understand the determinants of income levels, prior research suggests that the consequences of unemployment for human welfare are particularly pronounced and far exceed the effect of typical income changes on well-being (e.g., Blanchflower and Oswald, 2004). We suggest that given the range of long-run individual (e.g., reduced well-being, impaired employment prospects) and societal impacts (e.g., health service and welfare costs) associated with job loss (e.g., Clark et al., 2001; Daly and Delaney, 2013; Paul and Moser, 2009), it is now important to identify whether the long-term economic consequences of psychiatric conditions extend to unemployment. To date, just a single study has examined the link between mental health and unemployment using a sibling comparison design (Egan et al., 2016). The authors used a nationally representative American sample to show that participants reporting high levels of psychological distress in adolescence experienced an increased likelihood of unemployment over 12 years after adjustment for all environmental and genetic factors shared between siblings. However, this study relied on a self-reported mental health instrument which may be prone to underreporting (Eaton et al., 2000) and may fail to capture non-mood disorders when compared to the 'gold standard' of clinical diagnostic interviews (Rumpf et al., 2001).

In the current study, we incorporated sibling comparisons and moved beyond prior research by examining whether psychiatric conditions assessed via structured psychiatric interview in adolescence were predictive of unemployment throughout life. Specifically, psychiatric conditions were identified using the International Classification of Diseases (ICD), the international diagnostic classification standard for identifying the incidence of clinical conditions. Objective diagnoses of mental disorders are expected to minimize the possibility of biased self-assessments of mental health potentially influenced by individuals' tendency to present favourable images of themselves (Van de Mortel, 2008). This objective assessment of mental health allowed us to conduct an extensive examination of the relationships between diagnosed psychiatric conditions and unemployment as assessed through linkage to records from the Swedish Public Employment Services (PES).

In addition, linkage to administrative records enabled us to test whether those with psychological problems were more likely than others to become unemployed following the early 1990s economic crisis in Sweden. The 1990s Swedish economic crisis was triggered by monetary policy failures to deal with inflation, budget deficits, high interest rates, and a crash in the housing market (Englund, 1999). It led to a dramatic increase in unemployment, which rose from $1.6 \%$ in 1990 to $8.2 \%$ in 1993 . Alongside layoffs, employers relied increasingly on fixed-term temporary contracts in the aftermath of the crisis, together leading to a large increase in unemployment (Skans et al., 2009).

Workers with pre-existing psychological problems have been shown to bear disproportionately larger shares of the recession costs compared to those not suffering with low psychological well-being (e.g., Egan et al., 2015; Evans-Lacko et al., 2013). Those experiencing high levels of distress during childhood were more likely than others to become unemployed during the 1980 UK recession (Egan et al., 2015). Similarly, the unemployment penalty associated with pre-existing psychological distress was found to be significantly larger in the years after the Great Recession (Egan et al., 2016). In the Swedish context, those who had experienced prior hospitalisation for mental health issues were shown to be particularly vulnerable to job loss following the Swedish recession in the 1990s (Bharadwaj et al., 2015). We contribute to this literature by examining the early 1990s macro-economic shock. We hypothesized that this shock would amplify the detrimental effect of adolescent mental health conditions on future unemployment. During adverse economic conditions employers may tend to dismiss employees with a history of reduced work performance or absenteeism, a strategy that may disproportionally affect those with mental health conditions (Bubonya et al., 2016; Lagerveld et al., 2010; Lerner and Henke, 2008). Further, those with psychiatric conditions seeking work in competitive labour markets may have difficulty meeting the arduous demands of the job search-process and in meeting employer expectations of impression and time management during job interviews and internships. We anticipated that the uncertainty and stress associated with finding and retaining work in an economic recession may be most likely to impact the employment prospects of those diagnosed with neurotic and adjustment disorders, conditions closely related to anxiety proneness and difficulties in coping with life stressors. 


\section{Method}

\subsection{Study sample}

The total available sample consists of approximately a million and a half $(1,465,987)$ Swedish men and is drawn from the combination of multiple Swedish registries; mainly, the multi-generation register, the integrated database for labour market research (LISA) and the conscription register. All males who have complete military enlistment records and for whom at least one biological parent can be identified, are included in the original sample. These men, who were born between 1951 and 1976, enlisted in military services in the period between 1969 and 1994, when serving in the Swedish defence was mandatory for all males except those certified by a physician as severely diseased or disabled. The study was approved by the Regional Ethics committee, Stockholm, Sweden (2015/2097-31/1).

Using the 2012 migration and death registries, we could exclude those who had died (46,475 individuals) and those who had left the country (39,694 individuals). Those who were born after 1970 and those who conscripted from 1989 and onwards were also removed from the study sample (294,243 individuals). Those born after 1970 were aged around 14- to 19-years old at conscription and were, thus, likely still to be in education in 1990 when labour market events were first recorded. Additionally, we did not include in the sample those who had missing conscription information (156,399 individuals); for example, conscription year, conscription centre and county of residence at conscription. Finally, we identified a sample of 929,191 Swedish males for whom there is valid information on physical and mental health status at conscription and labour market trajectories between 1990 and 2012. For 407,099 individuals at least one full brother born between 1951 and 1976 could be identified in the sample and this sample of brothers was used to incorporate sibling fixed effects into our models.

The sample average age at conscription is 18.4 years, with minimum age being 16 years old and maximum age 26 years. The vast majority of the sample $(N=907,243 ; 97.6 \%)$ were 19 or younger when they went through conscription examinations. The oldest cohort members were born in 1950 and aged 40-63 years over the period from 1990 to 2012, when unemployment has been assessed. The youngest cohort members were born in 1970 and aged 20-42 years over the post-conscription follow-up period. Integrating multiple waves of conscription data allows the examination of unemployment over the full span of working life from young adulthood and almost to age of retirement, which is approximately 65 years of age in Sweden.

\subsection{Measures and methods}

\subsubsection{Adolescent psychiatric conditions}

Mental health diagnoses were registered as part of conscription examinations, when the sample were in their late adolescence. All those conscripted were interviewed by a psychologist. Where signs of psychiatric illness were detected, individuals were referred to a psychiatrist, who made a clinical diagnosis (Gale et al., 2014). It should be noted here that not all those who underwent the conscription examination went on to complete military service. It is likely that men who were diagnosed with mental health illness were more likely than others to have been exempted from the army, particularly in the cases of severe and disabling conditions. However, the data do not allow those with mental illness who served in the army to be distinguished from those who did not.

Diagnoses were grouped according to ICD-8 (1969-1986) and ICD-9 (1987-1989) codes as documented in prior papers (e.g., Gale et al., 2014). The following diagnostic categories were available in the dataset: depressive disorders; neurotic (e.g., anxiety) and adjustment disorders (e.g., transient situational disturbances); personality disorders (e.g., paranoid, anti-social); alcohol-related disorders; other substance use disorders; schizophrenia and other non-affective psychotic disorders (e.g., acute paranoid reaction); and bipolar disorders. A full breakdown of the range of disorders included within these categories and examined in our analyses appears in Table S1 in the Supplementary Materials. Potentially due to their severe and disabling nature, there was a low prevalence of schizophrenia and other psychotic disorders and bipolar disorders in the sample (193 and 32 individuals, respectively). As such, it was not possible to examine the relation between these diagnostic categories and future unemployment. However, those diagnosed with these conditions were included in our analyses of the overall effect of mental health. To do so, we produced an indicator detailing whether each subject has been diagnosed with 'any mental condition', having a prevalence of $6.5-7 \%$ in the full and the sibling samples.

\subsubsection{Unemployment}

Unemployment was observed each year from 1990 to 2012, using the records of the Swedish Public Employment Services (PES). This variable captures whether an individual was registered as unemployed at any point during each year. In Sweden, workers who are registered as unemployed are entitled to generous unemployment benefits that might be an incentive to register as unemployed among people who do not intend to work in the future. However, there is a system for monitoring the job seeking activities of unemployment benefits recipients in place. Moreover, PES can decide that benefits will be reduced or discontinued in the cases where recipients do not meet the job seeking requirements for unemployment benefits uptake. Therefore, we expect that this policy minimizes the risk of Swedish workers falsely registering as unemployed in order to benefit from the unemployment compensation.

The contrast group comprises all other forms of activities, including being employed and out of the labour force (e.g., due to disability or education). The number of days spent in unemployment was also recorded annually for the period between 1992 and 2012 .

Given that the unemployment indicator available in the LISA registry does not distinguish between the employed and the inactive groups, the effect of being diagnosed with mental illness on the probability of being unemployed versus being in employment cannot be directly inferred. To avoid underestimating the labour market effects of mental health, we focus on time spent in unemployment, using the annual average number of unemployment days during 1992-2012 as the primary outcome of interest. The variable equals zero for the study subjects who have never been registered as unemployed with the Swedish PES.

When examining the potential impact of the 1990s Swedish macroeconomic crisis, we use the binary indicator of whether the subject was unemployed in 1990 and/or 1991 as the number of days spent unemployed was not recorded in these years.

\subsubsection{Confounding and potential mediating factors}

Confounding factors, which could affect both the onset of mental conditions in adolescence and the likelihood of spending prolonged time in unemployment were controlled. Specifically, we adjusted for objectively recorded body mass index (BMI) levels (e.g., BMI has been linked to economic outcomes in this cohort; Lundborg et al., 2014), height, systolic and diastolic blood pressure and muscle strength. Age at conscription, year of testing, conscription testing centre, and county of residence are also controlled.

Maternal socio-economic background during childhood was measured using her occupational status ranging from one to seven ( $1=$ others $/$ not classified, 2 = unskilled worker, $3=$ skilled worker, $4=$ farmer/self-employed, 5 = non-manual worker at lower level, $6=$ non-manual worker at intermediate level, $7=$ non-manual worker at higher level). This categorical measure of occupational status, which is drawn from the Swedish Housing and Population Censuses between 1960 and 1990, is constructed based on the Swedish Socioeconomic Index (SEI) (Swedish National Central Bureau of Statistics, 1982). The SEI is a standard framework for classifying occupations that mainly 
distinguishes between manual and non-manual occupations. The two groups of occupations are further broken down by level of required educational qualifications - for example, skilled and unskilled workers in manual occupations and lower, intermediate, and high levels of education in non-manual occupations. The 'farmer/self-employed' category includes employers (self-employed professionals and farmers). The SEI classification has been shown to be a reliable proxy for adult socio-economic status in Sweden (see for example, Breen and Jonsson, 2007).

Further, we considered the influence of factors that may explain the link between adolescent mental health and unemployment; namely, cognitive ability and adult socio-economic status. To test whether cognitive skills could explain an association between mental health problems and future economic outcomes, we used a measure of intelligence based on scores achieved in conscription tests assessing verbal, technical, logical and spatial skills (with scores ranging from one to nine based on test performance). We used measures of educational attainment (from $1=$ less than 9 years to $7=P h D$ ) and adult occupational socioeconomic position categories $(1=$ others $/$ not classified, 2 = unskilled workers, $3=$ skilled workers, $4=$ farmers and self-employed, 5 = non-manual workers at lower level, 6 = non-manual workers at intermediate level, 7 = non-manual workers at higher level) to identify whether the detrimental repercussions of mental health are driven through selection into lower status jobs and/or inadequate accumulation of skills, as reflected in reduced educational achievement.

Standardised versions of all continuous variables, namely, BMI, height, systolic and diastolic blood pressure, muscle strength and cognitive ability scores, are included in the models.

\subsection{Analytical strategy}

We modelled adult unemployment as a function of adolescent mental health disorders and childhood and adult socio-economic background, using specification (Model 1) below, where Unemployment $t_{i}$ is the average number of days spent in unemployment per year during the period spanning from 1992 to 2012 .

Model 1:

Unemployment $_{i}=b_{0}+b_{1}$ Adolescent psychiatric conditions

$$
\begin{aligned}
& +b_{2} \text { Childhood background factors }_{i} \\
& +b_{3} \text { Adolescent physical health } \\
& +b_{4} \text { Adolescent intelligence }+b_{5} \text { Adolescent intelligence } \\
& +b_{5} S E S_{i}+e_{i}
\end{aligned}
$$

We added terms $b_{2}-b_{5}$ at separate stages in order to observe the process of gradually isolating the link between mental illness and subsequent unemployment. We included controls for cognitive ability and adult socioeconomic position and educational achievement at later stages to examine whether such factors may act as pathways linking mental health conditions to time spent in unemployment.

We estimate all models using the ordinary least squares (OLS) method instead of estimating negative binomial models (which account for over-dispersion in the main outcome of interest: unemployment days). This method was used because negative binomial models may fail to appropriately control for time-invariant covariates when estimated using fixed effects, as in our sibling models (e.g., Allison and Waterman, 2002). We also include supplementary tests re-estimating all models using negative binomial models.

Next, we accounted for family-specific characteristics that may have influenced both the likelihood of mental illness and poor performance in the labour market. To do this, we estimated specification (Model 2) below incorporating sibling fixed effects to adjust for unobserved confounding factors at the family level. Specifically, we estimated the below model using a subsample restricted to brothers where $j$ is an index indicating the family each individual belongs to.

Model 2:

Unemployment $_{i j}=b_{0}+b_{1}$ Adolescent psychiatric conditions $_{i j}$

$$
\begin{aligned}
& +b_{2} \text { Childhood background factors } s_{i j} \\
& +b_{3} \text { Adolescent physical health } \\
& +b_{4} \text { Adolescent intelligence }+b_{5} S E S_{i j}+s_{j}+e_{i j}
\end{aligned}
$$

The term $s_{j}$ stands for the sibling fixed effects, capturing the common family characteristics shared between siblings. Thus, we relied on within-family variation in the presence of psychiatric conditions at conscription in order to identify how these conditions relate to labour market outcomes. Identification in this analysis relied specifically on the $12.3 \%$ of the sibling sample who were discordant in diagnoses of mental conditions (i.e., siblings from families where at least one sibling was diagnosed with any mental condition at adolescence and at least one sibling was not diagnosed).

Our final objective was to examine whether the potential unemployment effects of psychiatric diagnoses in late adolescence were magnified during economic downturns. For this purpose, we adopted a difference-in-differences approach. In short, this method compares the differences in the probability of unemployment between those with and without mental disorders in the periods before and after the crisis. We estimate specification (Model 3):

Model 3:

Unemployment $_{i t}=c_{0}+c_{1}$ Adolescent psychiatric conditions $_{i}$

$$
\begin{aligned}
& +c_{2} \text { Adolescent background factors }_{i}+c_{3} \text { Recession }_{t} \\
& +c_{4} \text { Adolescent psychiatric conditions }_{i} * \text { Recession }_{t} \\
& +c_{5} \text { Adolescent physical health }_{i} \\
& +c_{6} \text { Adolescent intelligence }_{i}+e_{i t}
\end{aligned}
$$

where $c_{4}=\left[\right.$ (unemployment $_{\text {post-recession, psychiatric con. }}$.

$$
\begin{aligned}
& \text { - unemployment } \left.t_{\text {post-recession, others }}\right)
\end{aligned}
$$

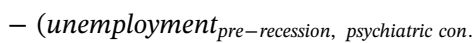

$$
\begin{aligned}
& \text { - unemployment } \left.{ }_{\text {pre-recession, others }}\right) \text { ] }
\end{aligned}
$$

The effect of interest is the interaction term $b_{4}$, which shows the difference between the impact of adolescent mental health on the probability of unemployment before and after the crisis. Unemployment $t_{i t}$ is the probability of being registered as unemployed in any given year of the period of interest. Recession ${ }_{t}$ is a binary indicator taking the value 1 for the post-crisis period and 0 for the years prior to the crisis. Because unemployment experiences are recorded only from 1990 onwards, years 1990 and 1991 are considered the period prior to the recession. The post-crisis era is defined as the time frame between 1993 and 1997. We select these five years in the period following the crisis to cover the whole era of the labour market decline (Bharadjwai et al., 2015; Holmlund, 2003). As it is ambiguous whether 1992 should be categorised in the pre- or post-recession period, it is not included in our analysis.

We fit a linear probability model to the observed data. We estimate specification (Model 3) using the ordinary least squares method to obtain the $c_{4}$ coefficient. Despite issues associated with utilising linear estimation in the prediction of probabilities, it has been shown that this approach can yield consistent and unbiased estimates of marginal effects, which do not differ substantially from the probit and logit outcomes (Angrist and Pischke, 2008; Wooldridge, 2003). 
Table 1

Descriptive statistics for the full $(N=929,191)$ and sibling $(N=407,099)$ samples.

\begin{tabular}{|c|c|c|c|c|c|c|}
\hline \multicolumn{2}{|l|}{ Diagnoses } & \multicolumn{2}{|c|}{ Full Sample } & \multicolumn{3}{|c|}{ Sibling Sample } \\
\hline & & $\%$ & $\mathrm{~N}$ & $\%$ & & $\mathrm{~N}$ \\
\hline Any psychiatric condition & & 7.06 & 65,585 & & 57 & 26,738 \\
\hline Depressive disorders & & 0.22 & 2052 & & 8 & 733 \\
\hline Neurotic/adjustment disorders & & 4.59 & 42,637 & & 3 & 17,219 \\
\hline Personality disorders & & 0.98 & 9130 & & 37 & 3532 \\
\hline Alcohol related disorders & & 0.29 & 2703 & & 28 & 1144 \\
\hline \multicolumn{2}{|l|}{ Other substance use disorders } & 0.45 & 4192 & & 1 & 1661 \\
\hline & Mean & SD & $\mathrm{N}$ & Mean & SD & $\mathrm{N}$ \\
\hline $\begin{array}{l}\text { Unemployment (days per } \\
\text { year) }\end{array}$ & 16.73 & 28.97 & 929,191 & 16.82 & 28.92 & 407,099 \\
\hline Age at conscription & 18.44 & 0.68 & 929,191 & 18.40 & 0.66 & 407,099 \\
\hline Maternal social status ${ }^{b}$ & 3.61 & 1.50 & 921,970 & 3.63 & 1.48 & 405,784 \\
\hline Height (cm) & 179.0 & 6.49 & 916,841 & 178.9 & 6.50 & 402,364 \\
\hline BMI $\left(\mathrm{kg} / \mathrm{m}^{2}\right)$ & 21.53 & 2.76 & 916,570 & 21.51 & 2.72 & 402,247 \\
\hline Systolic blood pressure ${ }^{c}$ & 128.4 & 10.95 & 916,788 & 128.4 & 10.91 & 402,335 \\
\hline Diastolic blood pressure $^{c}$ & 67.80 & 9.88 & 916,667 & 67.29 & 9.90 & 402,265 \\
\hline Muscle strength & 2080 & 311.3 & 916,489 & 2084 & 313.5 & 402,165 \\
\hline Cognitive ability & 5.17 & 1.94 & 919,532 & 5.11 & 1.95 & 403,530 \\
\hline Educational achievement $^{\mathrm{d}}$ & 3.77 & 1.39 & 928,190 & 3.75 & 1.39 & 406,665 \\
\hline $\begin{array}{l}\text { Own occupational } \\
\text { socioeconomic position }\end{array}$ & 3.38 & 1.95 & 926,913 & 3.31 & 1.91 & 406,235 \\
\hline
\end{tabular}

a Average number of days spent in unemployment per year during the period between 1992 and 2012.

b Categorical variable.

c Measured in mmHg.

${ }^{\mathrm{d}}$ From $1=$ less than 9 years to $7=\mathrm{PhD}$ (variable treated as categorical in main analyses).

e Categorical variable, measured in 1990.

\section{Results}

\subsection{Descriptive statistics}

Table 1 presents the descriptive statistics for all the key variables used in our analyses for both the overall sample and the sibling subsample. Both the prevalence of mental conditions and the distribution of the covariates in the sibling sample are similar to those of the full sample, indicating that the latter is representative of the study population. Moreover, there are no major differences in the average number of days spent unemployed between the full and sibling sample groups. As shown in Table 1, the neurotic and adjustment disorders group had the highest prevalence $(4.6 \%)$ in both samples. Despite depression being a relatively common mental health problem, a very small share of study subjects were diagnosed with depressive disorders. This low share likely reflects the nature of the set of depressive conditions diagnosed at enlistment which was restricted to depressive conditions associated with persistent impairment (e.g., depressive neurosis: Bronisch et al., 1985) and psychosis (e.g., reactive depressive psychosis, manic-depressive psychosis) (see Supplemental Materials, Table S1). Amongst those included in the study missing data levels were very low and the small portion of missing observations present $(<1 \%)$ were replaced using mean imputation.

In Supplementary Material Tables S2 and S3, the distribution of the main variables is shown by psychiatric diagnoses for both the siblings and the full sample. Fig. 1 shows the average number of days spent in unemployment per year and unemployment levels for each year between 1992 and 2012 for those with (27.5 days spent unemployed per year) and without (17.7 days) any diagnosed psychiatric conditions. Figs. S1 and S2 in the Supplemental Materials display the annual unemployment days and levels by each diagnostic category.

\subsection{Adolescent psychiatric conditions and unemployment in adulthood}

First, we examined the potential effect of being diagnosed with any mental health condition using the full sample of those conscripted. The results of estimating Model 1, described above, appear in Table 2. After adjusting for maternal socioeconomic status and adolescent physical health, those diagnosed with any type of psychiatric condition in late adolescence spent approximately 10 more days unemployed per year than the remainder of the sample. Alcohol and other substance related disorders were most closely related to future performance in the labour market, being associated with 16 and 17 more days in unemployment per year, respectively. Personality disorders predicted around 10 more unemployment days, while neurotic and adjustment conditions were associated with nine days of additional unemployment annually. Although depression has been identified as a key determinant of labour market adversities (e.g., Fletcher, 2013), it had the weakest association with unemployment in our sample (six days per year).

Those diagnosed with psychiatric conditions had lower cognitive ability scores and a 1-SD increase in cognitive ability predicted 4.7 fewer days unemployment per year. Cognitive ability appeared to explain approximately $23 \%$ of the link between suffering from any psychiatric condition and unemployment. This explanatory effect did not appear to vary markedly between diagnostic categories. Highest educational achievement had a direct effect on future unemployment but did not appear to confound or mediate the relationship between adolescent mental health and subsequent unemployment, after having adjusted for maternal socio-economic background, adolescent physical health, and cognitive ability. Adult occupational socioeconomic position explained $14 \%$ of the remaining link between adolescent mental health and adult unemployment. Specifically, those suffering from psychiatric conditions in adolescence were more likely to find themselves in low status jobs which were associated with an enhanced likelihood of unemployment. In the model adjusted for covariates and potential mediators, being diagnosed with any psychiatric condition in adolescence was associated with 6.7 additional days of unemployment per year between 1992 and 2012. The strength of this association varied between psychiatric conditions. Depressive disorders predicted four more days in unemployment per year, while personality and neurotic conditions were associated with around seven and six more unemployment days, respectively. Alcohol and drug dependence were associated with the greatest risk, predicting approximately 10 and 12 more unemployment days on an annual basis, respectively.

\subsection{Sibling fixed-effects models}

Table S4 in the Supplementary Materials displays the results of reestimating Model 1, using the available subsample of Swedish male siblings. Prior to adjustment for sibling fixed effects the links between adolescent psychiatric symptoms and subsequent unemployment in the sibling subsample, are of similar magnitude and direction compared to those estimated using the full sample.

Table 3 presents the key sibling fixed effects results derived from estimating Model 2. Adjusting for unobserved family effects attenuated the link between any psychiatric condition and unemployment by $47 \%$ compared to the full sample estimates, as illustrated in Fig. 2. Similarly, when examining individual conditions, with the exception of depressive disorder, adjusting for the influence of the shared family environment among siblings led to approximately a $47 \%$ decrease in strength of the link between each individual adolescent mental condition and future unemployment.

The impact of any adolescent mental health conditions and of neurotic and adjustment disorders/personality disorder/alcohol-related disorder/other substance use disorder was not fully explained by family characteristics and remained highly statistically significant. In contrast, the link between depressive disorder and future unemployment was attenuated markedly to non-significance after adjustment for the family 

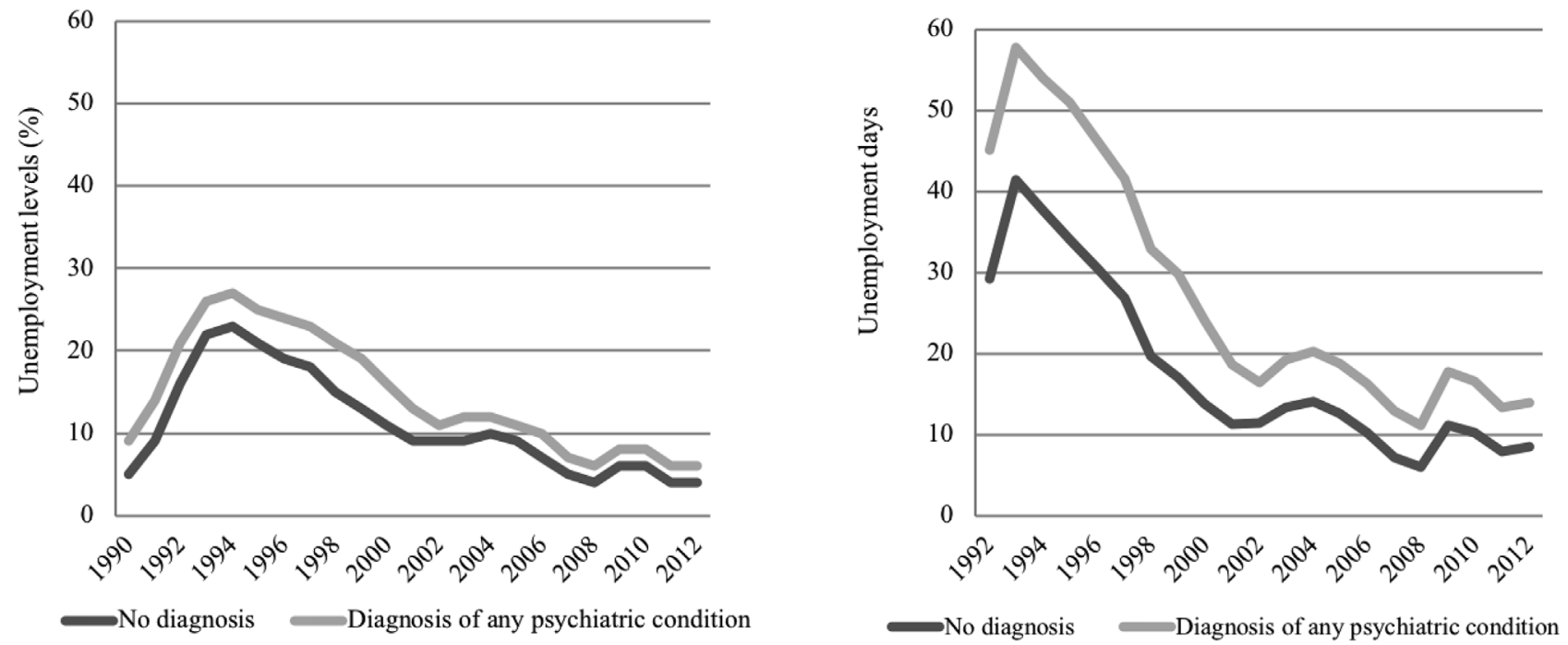

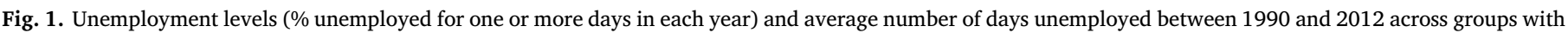
and without any diagnosed mental health condition.

Table 2

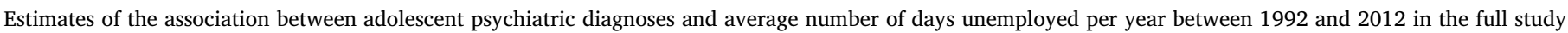
sample $(N=929,191)$.

\begin{tabular}{|c|c|c|c|c|c|c|}
\hline Diagnostic Categories & Conscription $^{\mathrm{a}}$ & Childhood SES $^{b}$ & Physical health ${ }^{c}$ & Cognitive ability $^{\mathrm{d}}$ & Education $^{\mathrm{e}}$ & Own SES ${ }^{f}$ \\
\hline \multirow[t]{2}{*}{ Any psychiatric condition } & $11.19^{* * *}$ & $10.56^{* * *}$ & $9.97^{* * *}$ & $7.65^{* * *}$ & $7.86^{* * *}$ & $6.73^{* * *}$ \\
\hline & $(0.15)$ & $(0.15)$ & $(0.15)$ & $(0.15)$ & $(0.15)$ & $(0.14)$ \\
\hline \multirow[t]{2}{*}{ Depressive disorders } & $7.05^{* * *}$ & $6.83^{* * *}$ & $6.35 * * *$ & $5.31 * * *$ & $5.35^{* * *}$ & $4.11^{* * *}$ \\
\hline & $(0.77)$ & $(0.77)$ & $(0.77)$ & $(0.77)$ & $(0.76)$ & $(0.76)$ \\
\hline \multirow[t]{2}{*}{ Neurotic disorders } & $10.16^{* * *}$ & $9.56^{* * *}$ & $8.95^{* * *}$ & $6.83^{* * *}$ & $7.01^{* * *}$ & $6.15^{* * *}$ \\
\hline & $(0.18)$ & $(0.18)$ & $(0.18)$ & $(0.18)$ & $(0.18)$ & $(0.17)$ \\
\hline \multirow[t]{2}{*}{ Personality disorders } & $12.48^{* * *}$ & $11.75^{* * *}$ & $10.10^{* * *}$ & $8.44 * * *$ & $8.70^{* * *}$ & $6.95^{* * *}$ \\
\hline & $(0.40)$ & $(0.40)$ & $(0.40)$ & $(0.40)$ & $(0.40)$ & $(0.39)$ \\
\hline \multirow[t]{2}{*}{ Alcohol-related disorders } & $17.73^{* * *}$ & $16.62^{* * *}$ & $15.90 * * *$ & $12.22^{* * *}$ & $12.57 * * *$ & $10.45^{* * *}$ \\
\hline & $(0.78)$ & $(0.77)$ & $(0.77)$ & $(0.78)$ & $(0.77)$ & $(0.77)$ \\
\hline \multirow[t]{2}{*}{ Other substance use disorders } & $19.00^{* * *}$ & $18.19^{* * *}$ & $17.19^{* * *}$ & $14.83^{* * *}$ & $14.82^{* * *}$ & $12.08^{* * *}$ \\
\hline & $(0.62)$ & $(0.62)$ & $(0.63)$ & $(0.63)$ & $(0.62)$ & $(0.62)$ \\
\hline
\end{tabular}

Note. Robust standard errors appear in parentheses.

$* * * p<0.001, * * p<0.01, * p<0.05$.

a Conscription age, conscription year, conscription centre and county of residence controls are included.

b Controls for maternal socio-economic background are added.

c Controls for physical health assessed at conscription are added.

d Cognitive ability results from tests at conscription are added.

e Controls for highest educational qualification are added.

${ }^{\mathrm{f}}$ Controls for own occupational status in 1990 are added.

environment. It should be noted that the share of groups of siblings who are discordant in depressive disorders is quite low in the study sample, potentially limiting the identification of the impact of depressive disorders on adult unemployment.

Overall, these findings suggest that unobserved shared family background characteristics (e.g., an adverse family environment or parental mental health problems) are correlated with both adolescent mental health and lifelong labour market prospects and partially explain why these variables are interrelated.

\subsection{Adolescent mental conditions and unemployment during the 1990 s Swedish crisis}

The differences in the marginal effects of being diagnosed with adolescent psychiatric symptoms on the average predicted probability of being unemployed before and after the crisis are presented in Table 4. Model 3 is estimated in both the full and siblings' samples, yielding consistent results. In the pre-crisis period those diagnosed with psychiatric conditions experienced a 2.9 percentage point (pp) higher level of unemployment than others and this increased to a $4.4 \mathrm{pp}$ difference after the crisis. Our difference-in-differences models revealed that those diagnosed with any psychiatric condition faced a statistically significant $1.4 \mathrm{pp}$ increased risk of unemployment from the pre-to postcrisis period (an approximately $50 \%$ increase from a 2.9 pp to a $4.4 \mathrm{pp}$ gap), as shown in Fig. S3.

Those who had been diagnosed with neurotic- and adjustment-related disorders appeared to be most affected by the recession. This group experienced an increase in the predicted probability of unemployment of $1.7 \mathrm{pp}$ from before to after the crisis (an increase of $63 \%$ from a 2.7 pp to a 4.4 pp difference in unemployment levels between those with neurotic/adjustment disorders and others). The worsening labour market conditions in the aftermath of the financial crisis also led to a rise in the risk of unemployment among those diagnosed with alcohol-related disorders compared to others' 1.2 pp increased risk from 
Table 3

Sibling fixed-effects estimates of the effects of psychiatric diagnoses on average number of days unemployed per year between 1992 and $2012(N=407,099)$.

\begin{tabular}{|c|c|c|c|c|c|c|}
\hline Conditions & Conscription $^{\mathrm{a}}$ & Childhood SES $^{\mathrm{b}}$ & Physical health $^{c}$ & Cognitive ability $^{\mathrm{d}}$ & Education $^{\mathrm{e}}$ & Own SES ${ }^{f}$ \\
\hline Any psychiatric condition & $\begin{array}{l}5.16^{* * *} \\
(0.30)\end{array}$ & $\begin{array}{l}5.16^{* * *} \\
(0.30)\end{array}$ & $\begin{array}{l}4.92 * * * \\
(0.31)\end{array}$ & $\begin{array}{l}3.87 * * * \\
(0.31)\end{array}$ & $\begin{array}{l}4.05^{* * *} \\
(0.30)\end{array}$ & $\begin{array}{l}3.57 * * * \\
(0.30)\end{array}$ \\
\hline Depressive disorders & $\begin{array}{l}1.82 \\
(1.56)\end{array}$ & $\begin{array}{l}1.83 \\
(1.56)\end{array}$ & $\begin{array}{l}1.54 \\
(1.56)\end{array}$ & $\begin{array}{l}1.04 \\
(1.57)\end{array}$ & $\begin{array}{l}1.00 \\
(1.55)\end{array}$ & $\begin{array}{l}0.44 \\
(1.54)\end{array}$ \\
\hline Neurotic and adjustment & $\begin{array}{l}4.67 * * * \\
(0.36)\end{array}$ & $\begin{array}{l}4.66^{* * *} \\
(0.36)\end{array}$ & $\begin{array}{l}4.43^{* * *} \\
(0.36)\end{array}$ & $\begin{array}{l}3.47^{* * * *} \\
(0.36)\end{array}$ & $\begin{array}{l}3.63^{* * *} \\
(0.36)\end{array}$ & $\begin{array}{l}3.27^{* * *} \\
(0.36)\end{array}$ \\
\hline Personality disorders & $\begin{array}{l}5.27^{* * *} \\
(0.82)\end{array}$ & $\begin{array}{l}5.28^{* * * *} \\
(0.82)\end{array}$ & $\begin{array}{l}5.07^{* * *} \\
(0.82)\end{array}$ & $\begin{array}{l}4.02^{* * * *} \\
(0.82)\end{array}$ & $\begin{array}{l}4.28^{* * *} \\
(0.81)\end{array}$ & $\begin{array}{l}3.65^{* * *} \\
(0.80)\end{array}$ \\
\hline Alcohol-related disorders & $\begin{array}{l}6.67^{* * *} \\
(1.57)\end{array}$ & $\begin{array}{l}6.67^{* * *} \\
(1.57)\end{array}$ & $\begin{array}{l}6.45^{* * *} \\
(1.57)\end{array}$ & $\begin{array}{l}5.38 * * * \\
(1.57)\end{array}$ & $\begin{array}{l}5.73^{* * *} \\
(1.56)\end{array}$ & $\begin{array}{l}4.96^{* *} \\
(1.54)\end{array}$ \\
\hline Other substance use disorders & $\begin{array}{l}9.47^{* * *} \\
(1.32)\end{array}$ & $\begin{array}{l}9.47^{* * *} \\
(1.32)\end{array}$ & $\begin{array}{l}9.12^{* * *} \\
(1.32)\end{array}$ & $\begin{array}{l}8.13^{* * *} \\
(1.31)\end{array}$ & $\begin{array}{l}8.27^{* * *} \\
(1.30)\end{array}$ & $\begin{array}{l}6.87^{* * *} \\
(1.29)\end{array}$ \\
\hline
\end{tabular}

Note. Robust standard errors appear in parentheses.

$* * * p<0.001, * * p<0.01, * p<0.05$.

a Conscription age, conscription year, conscription centre and county of residence controls are included.

b Controls for maternal socio-economic background are added.

c Controls for physical health assessed at conscription are added.

d Cognitive ability results from tests at conscription are added.

e Controls for highest educational qualification are added.

f Controls for own occupational status in 1990 are added.

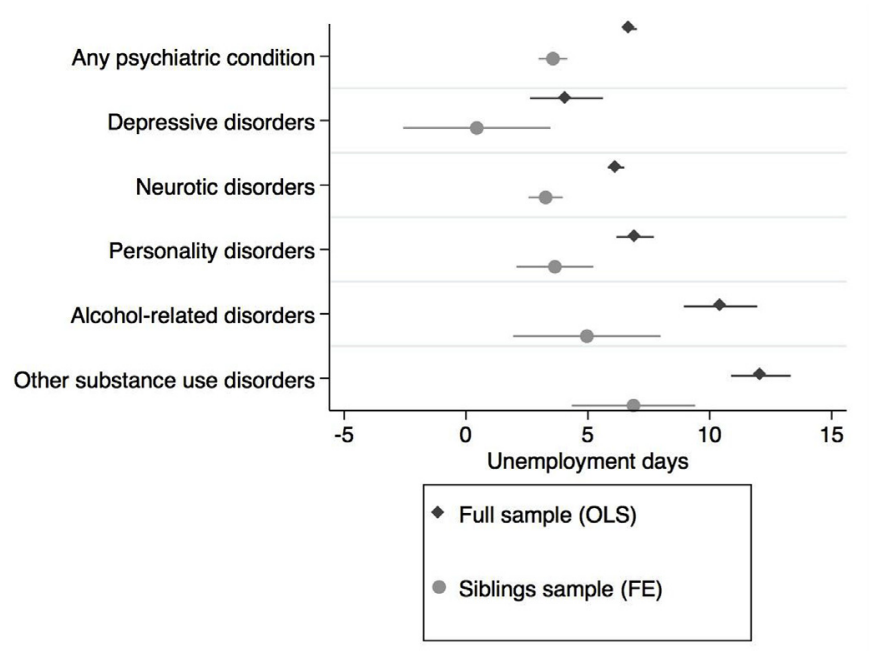

Fig. 2. Fully adjusted estimates of the effect of psychiatric conditions on the average number of days spent in unemployment per year by diagnostic category in the full sample analyses and the sibling fixed effects models. the pre-to post-crisis period (an increase of $25 \%$ from a $5.3 \mathrm{pp}$ to a 6.6 pp gap). Thus, the observed increase in the strength of the association between mental health and unemployment from before to after the financial crisis was likely to be largely attributable to the elevated impact of the crisis on those diagnosed with neurotic and adjustment conditions or alcohol abuse and dependence.

\subsection{Supplementary robustness tests}

Because the main outcome (days spent in unemployment per year) is over-dispersed, in addition to the OLS estimations reported above we fit a negative binomial model to adjust for over-dispersion in the number of days spent in unemployment during each year. As shown in Fig. S4 in the Supplementary Materials, the two techniques evidently result in estimates that do not differ substantially.

We also conducted additional analyses removing those who were aged over 19 at conscription (3\% of the sample) as this group may have accumulated labour market experience at this point. As detailed in Tables S5-S7 in the Supplementary Materials, we found effects of the same magnitude and direction when excluding Swedish males who were older than 19-years old at conscription from the samples.

Finally, we used an annually recorded indicator of disability pension/benefit take-up to identify study subjects who were likely to be out

Table 4

Difference-in-differences estimates of the link between adolescent psychiatric diagnoses and the probability of unemployment before (1990-1991) and after (1993-1997) the 1990s financial crisis in the full $(N=929,191)$ and sibling $(N=407,099)$ samples.

\begin{tabular}{|c|c|c|c|c|c|c|}
\hline \multirow[t]{2}{*}{ Disorder Diagnoses } & \multicolumn{3}{|l|}{ Full Sample } & \multicolumn{3}{|l|}{ Sibling sample } \\
\hline & Pre-Crisis & Post-Crisis & $\operatorname{DiD}^{\mathrm{a}}$ & Pre-Crisis & Post-Crisis & $\mathrm{DiD}^{\mathrm{a}}$ \\
\hline Any psychiatric condition & $0.029 * * *(0.001)$ & $0.044 * * *(0.001)$ & $0.014 * * *(0.001)$ & $0.030 * * *(0.001)$ & $0.046^{* * *}(0.001)$ & $0.016^{* * *}(0.002)$ \\
\hline Depressive disorders & $0.034 * *(0.005)$ & $0.019 * *(0.004)$ & $-0.014(0.006)$ & $0.020 * * *(0.007)$ & $0.009(0.006)$ & $-0.012(0.010)$ \\
\hline Neurotic/adjustment & $0.027 * * *(0.001)$ & $0.044 * * *(0.001)$ & $0.017 * * *(0.001)$ & $0.027 * * *(0.002)$ & $0.048 * * *(0.003)$ & $0.021^{* * *}(0.002)$ \\
\hline Personality disorders & $0.031 * * *(0.002)$ & $0.035^{* * *}(0.002)$ & $0.003(0.003)$ & $0.033^{* * *}(0.004)$ & $0.035^{* * *}(0.003)$ & $0.002(0.005)$ \\
\hline Alcohol-related disorders & $0.053^{* * *}(0.005)$ & $0.066^{* * *}(0.004)$ & $0.012^{* * *}(0.006)$ & $0.051^{* * *}(0.008)$ & $0.070 * * *(0.006)$ & $0.019^{* *}(0.010)$ \\
\hline Other substance use disorders & $0.054 * *(0.004)$ & $0.058^{* * *}(0.003)$ & $0.002(0.005)$ & $0.065^{* * *}(0.007)$ & $0.054 * * *(0.005)$ & $-0.011(0.008)$ \\
\hline$N$ & 929,191 & 929,191 & 929,191 & 407,099 & 407,099 & 407,099 \\
\hline Person-year observations & $1,853,432$ & $4,621,003$ & $6,474,435$ & 812,312 & $2,025,236$ & $2,837,548$ \\
\hline
\end{tabular}

Note. Robust standard errors, clustered at the individual level, appear in parentheses.

$* * * p<0.001, * * p<0.01, * p<0.05$.

${ }^{a}$ All reported marginal effects are calculated based on the estimation of difference-in-differences linear probability models including all covariates. The DiD

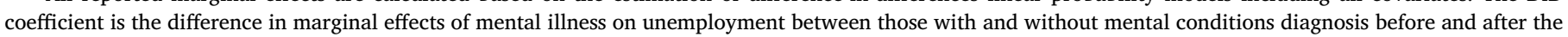
crisis. 
of the labour force. In Sweden, young workers with mental illness are disproportionately represented in the group receiving disability assistance and are likely to drop out of the labour market because of longstanding illness (OECD, 2013). Thus, including such workers in the sample might mask the real risk of unemployment faced by workers who are actively participating in the labour market and result in underestimation of the true effects. Excluding workers who received disability benefits at least once during the period between 1992 and 2012, resulted in larger effects of adolescent mental health conditions on future unemployment (see Supplementary Materials Tables S8-S10). These findings suggest that the impact of adolescent mental illness on adult unemployment outcomes might have been underestimated because data limitations did not allow to adjust for the selection of workers with psychiatric conditions out of the labour force.

\section{Discussion}

Our results showed that psychiatric conditions diagnosed in late adolescence forecasted unemployment across the lifespan in a population sample of male Swedish workers. The long-term influence of prelabour market mental health could not be attributed to variation in childhood socioeconomic status, family background, or objectively recorded indicators of adolescent physical health. Further, the predictive power of adolescent mental health exceeded that of a 1-SD change in cognitive ability, typically the strongest predictor of labour market outcomes.

A key strength of the data used in this study is that specific types of adolescent mental health conditions were diagnosed by psychiatrists, which allowed us to clarify the strength of the contribution of neurotic and adjustment, depressive, personality, alcohol and other substance use related disorders to subsequent unemployment. Drawing on over two decades of records from the Swedish Public Employment Services, our findings suggest that alcohol and other substance dependence disorders are most closely associated with a higher cumulative duration of unemployment. This finding aligns closely with previous work that has isolated the link between alcohol and substance use and reduced earnings in the United States (e.g., Smith and Smith, 2010) and Sweden (Lundborg et al., 2014a,b). In contrast, depressive disorders which have been previously shown to forecast labour market outcomes (e.g., Fletcher, 2013) were not substantially associated with unemployment in this sample. However, the larger category of neurotic and adjustment disorders, which is more inclusive and contains related affective disorders, was robustly related to subsequent unemployment.

Assessing the impact of ICD categories of mental disorders on adult unemployment outcomes builds on prior work that has attempted to identify potential variations in the labour market impacts of different types of mental health disorders. For example, Ettner et al. (1997) found indications in the data that alcohol dependence may be associated with greater declines in probability of employment compared to other disorders among American male workers. Methodological limitations did not allow the authors to explicitly distinguish between the impact of each type of mental disorder. Moreover, Kessler \& Frank (1997) uncover some evidence that affective disorders, such as major depressive disorders, are associated with more severe work impairment compared to substance use and anxiety disorders. However, this analysis was based on retrospective self-reports of workers that could have been exaggerated because of pessimistic perceptions of functioning at work among people with depressive disorders (Coyne and Gotlib, 1983).

An advantage of the data used in the study is that it was possible to use a subsample of 400,000 siblings to compare the labour market outcomes of brothers and control for all unobserved shared family characteristics. Specifically, by exploiting sibling clusters we could show that on average a sibling diagnosed with a psychiatric condition at conscription experienced more unemployment throughout life than a sibling with no diagnosed condition, which was the case for all psychiatric conditions examined with the exception of depressive disorder, which was no longer related to unemployment after adjustment for family fixed-effects. Overall, in contrast to prior work (e.g., Egan et al., 2016), our sibling analyses suggested that it is crucial to adjust for unobserved family characteristics in order to accurately estimate the magnitude of the relationship between adolescent mental health and unemployment. Further research is needed to identify the specific family background factors (e.g., unmeasured aspects of socioeconomic status, childhood adversities such as inadequate parenting, parental divorce, exposure to parental mental health problems) that if not considered will bias estimates of the association of adolescent mental health with unemployment in later life.

A third major contribution of the present study is that we explored the influence of a major economic downturn on the career prospects of workers with pre-existing mental health conditions. We showed that the early 1990s Swedish recession, which resulted in an unprecedented shock to the labour market, increased the unemployment penalty associated with poor mental health. On average, the increased risk of unemployment among those suffering from a psychiatric condition grew by $50 \%$ in the period following the shock. Those who had been diagnosed with neurotic and adjustment disorders, conditions related to problems in coping with significant life stressors, showed the largest relative increase in risk of unemployment following the recession. Similarly, those suffering from alcohol-related conditions showed a marked increase in vulnerability to unemployment after the crisis. While those with psychological problems have been shown to be disproportionally more likely to become unemployed following economic recessions (e.g., Egan et al., 2015; Egan et al., 2016; Evans Lacko et al., 2013), the present findings point to variation in the labour market effects of specific types of mental illness during times of economic hardship.

Further, we explored a set of potential pathways connecting adolescent mental health to labour market success. We found little evidence that academic disengagement or an increased risk of school dropout (Fletcher, 2010) curtailed the employment prospects of those diagnosed with psychiatric conditions. In contrast, occupational prestige appeared to have some explanatory power: Those diagnosed with psychiatric conditions tended to select into less secure manual and lowskilled occupations early in their careers, which weakened their attachment to the labour market throughout their careers (Bartley and Owen, 1996). Those with adolescent mental health problems also tended to have lower levels of cognitive ability which predicted an increased risk of unemployment. The explanatory power of cognitive ability may reflect either: (i) confounding (Daly, 2011) whereby intelligence may be the "true cause" of part of the association between psychiatric diagnoses and unemployment (Gale et al., 2010), or (ii) mediation whereby psychological problems may negatively affect the development of cognitive skills (e.g., Brown et al., 2000), causing subsequent adverse employment outcomes.

Finally, evidence suggests that adolescent mental health disorders are key risk factors for mental ill health during adulthood (see for example, Fryers and Brugha, 2013; Copeland et al., 2009). As adult mental health disorders are shown to predict unemployment (e.g., Banerjee et al., 2015; Chatterji et al., 2011), it is highly likely that the persistence of mental health problems into adulthood represents a key pathway linking adolescent psychiatric disorders to adverse labour market outcomes such as unemployment in adulthood. Further research is necessary to explore the extent to which adult mental health problems explain the link between adolescent diagnoses and future employment prospects.

\subsection{Limitations}

The present study faced a number of key limitations. First, while we could shed some light on potential mediating pathways, there are many other reasons why psychiatric conditions could contribute to 
unemployment that were not assessed in this study. For those out of work, mental health problems may impair their ability to search efficiently for jobs, engage effectively in impression management during the interview process, and re-enter employment quickly (Paul and Moser, 2009). Those in employment may be more likely to be absent or to experience reductions in job performance due to their mental health, which could adversely affect the likelihood of being retained by employers (Lerner and Henke, 2008). Further, the adverse labour market effects of psychiatric conditions may be exacerbated in the presence of mental health stigma and discriminatory work practices (Rüsch et al., 2005). As such, further research and detailed assessment is needed to precisely delineate why unemployment tends to be a consequence of poor mental health and the contexts where this is most likely to occur.

Another key limitation is that due to data constraints, we were not able to definitively identify workers who were out of the labour force. Therefore, we examined the effect of adolescent mental health on the likelihood of unemployment relative to being employed or out of the labour force. However, many individuals diagnosed with psychiatric conditions are likely to have been out of the labour force, which we suggest is likely to have biased our estimates downwards. In support of this idea our sensitivity tests which excluded a subgroup who were likely to be outside of the labour force (those in receipt of disability pension/benefit) showed a slightly stronger association between adolescent psychiatric conditions and employment prospects. Further research is needed to decipher whether examining the employment effects of psychiatric conditions among those known to be actively participating in the labour market would yield notably different estimates to those identified in this study.

Third, our focus in the present study was on males, so we do not know whether the same pattern of findings would be identified among females. Meta-analytical evidence indicates that the association between psychological distress and unemployment tends to be stronger in males than females (Paul and Moser, 2009). Further, the close link between mental health problems and unemployment among men may be particularly evident during times of economic recession (EvansLacko et al., 2013). However, the largely cross-sectional nature of this work means we cannot rule out the possibility of reverse causality: Males may suffer greater psychological effects of unemployment than females, as perhaps masculine identity is particularly threatened by job loss. As such, longitudinal research is now needed to test whether the potential impact of psychiatric conditions on finding and retaining employment throughout life differs between males and females.

Although our sibling models represented an extensive adjustment for unobserved aspects of the family environment as well as the portion of genetic variation shared between siblings, it remains difficult to ascertain whether omitted variables may have biased our estimates. For instance, it was not possible to adjust for potentially important personality traits such as conscientiousness and self-control that have been shown to predict a reduced risk of both mental health problems and unemployment (Daly et al., 2015; Egan et al., 2017; Hakulinen et al., 2015). While further work is needed to stringently isolate the specific contribution of psychiatric conditions to unemployment, based on prior work (e.g. Egan et al., 2015; Lundborg et al., 2014a,b) we anticipate that omitting non-cognitive traits such as self-control may not have markedly affected our results.

Finally, while not all men who were assessed at conscription went on to serve in the army, the data did not allow those who served to be distinguished from those who did not. Therefore, we cannot rule out the possibility that military service might influence the employment prospects of people with mental illness. While existing evidence on the impact of compulsory military service on future earnings is contradictory (see, for example, Hubers and Webbing, 2015; Grenet et al., 2011), potential labour market effects of serving in the army have not been studied explicitly for conscripts with mental health problems.

Moreover, as people with mental health problems may have been more likely to be exempted from military service, it is possible that potential conscripts either simulated or dissimulated symptoms of mental illness in order to avoid military service or to ensure they had the opportunity to serve. For example, it is possible that men who were employed or in education at the time of conscription might simulate mental illness symptoms in order to avoid military service. Not being able to address this possibility could result in measurement error in the assessment of diagnosed psychiatric conditions and an underestimation of the association between adolescent mental health and subsequent unemployment.

\section{Conclusions}

In summary, our results underscore the importance of psychiatric disorders in shaping lifelong trajectories in the labour market. Prior work has documented the substantial economic costs arising from childhood and adolescent mental health problems due to their effect on educational attainment and financial success throughout life (Fletcher, 2010; Goodman et al., 2011; Layard, 2013). Our study identifies another enduring economic cost of psychiatric conditions, unemployment, which is known to have profound effects on individual earnings and subsequent mental health (Clark et al., 2001; Paul and Moser, 2009).

Our findings point to the importance of investment in childhood and adolescent mental health treatment programs, which may yield substantial returns by improving the employment prospects and lifelong welfare of those treated. They point specifically to the need to invest in the prevention of adolescent alcohol and substance use problems, which hinder future employment opportunities. Investment in Active Labour Market Programmes (ALMPs) could enhance the employment prospects of those with mental health problems and/or curb the exacerbation of mental health problems during unemployment (Stuckler et al., 2009). There is also scope for further prioritizing the mental health and well-being of job seekers within the design of activation schemes. In line with this suggestion, a recent meta-analysis indicated that job search and training schemes are more effective in motivating workers to regain employment when steps are taken to promote participants' psychological well-being including fostering self-confidence and emphasizing social support (Liu et al., 2014).

\section{Appendix A. Supplementary data}

Supplementary data to this article can be found online at https:// doi.org/10.1016/j.socscimed.2018.12.030.

\section{References}

Allison, P.D., Waterman, R.P., 2002. Fixed-effects negative binomial regression models. Socio. Methodol. 32, 247-265.

Angrist, J.D., Pischke, J.S., 2008. Mostly Harmless Econometrics: an Empiricist's Companion. Princeton University Press, Princeton, NJ.

Banerjee, S., Chatterji, P., Lahiri, K., 2015. Effects of psychiatric disorders on labor market outcomes: a latent variable approach using multiple clinical indicators. Health Econ. $26,184-205$.

Bartley, M., Owen, C., 1996. Relation between socioeconomic status, employment, and health during economic change, 1973-93. BMJ 313, 445-449.

Bharadwaj, P., Lundborg, P., Rooth, D.O., 2015. Health and Unemployment during Macroeconomic Crises (No. W21353). National Bureau of Economic Research.

Blanchflower, D.G., Oswald, A.J., 2004. Well-being over time in Britain and the USA. J. Publ. Econ. 88, 1359-1386.

Breen, R., Jonsson, J.O., 2007. Explaining change in social fluidity: educational equalization and educational expansion in twentieth-century Sweden. Am. J. Sociol. 112 (6), 1775-1810.

Bronisch, T., Wittchen, H.U., Krieg, C., Rupp, H.U., Zerssen, D.V., 1985. Depressive neurosis: a long-term prospective and retrospective follow-up study of former inpatients. Acta Psychiatr. Scand. 71, 237-248.

Brown, S.A., Tapert, S.F., Granholm, E., Delis, D.C., 2000. Neurocognitive functioning of adolescents: effects of protracted alcohol use. Alcohol Clin. Exp. Res. 24, 164-171.

Bubonya, M., Cobb-Clark, D.A., Wooden, M., 2016. Mental Health and Productivity at Work: Does what You Do Matter. Melbourne Institute Working Paper No. 16/16.

Butterworth, P., Leach, L.S., Pirkis, J., Kelaher, M., 2012. Poor mental health influences risk and duration of unemployment: a prospective study. Soc. Psychiatr. Psychiatr. Epidemiol. 47, 1013-1021.

Chatterji, P., Alegria, M., Takeuchi, D., 2011. Psychiatric disorders and labor market 
outcomes: evidence from the National Comorbidity Survey-Replication. J. Health Econ. 30, 858-868.

Clark, A., Georgellis, Y., Sanfey, P., 2001. Scarring: the psychological impact of past unemployment. Economica 68, 221-241.

Copeland, W.E., Shanahan, L., Costello, E.J., Angold, A., 2009. Childhood and adolescent psychiatric disorders as predictors of young adult disorders. Arch. Gen. Psychiatr. 66 (7), 764-772.

Coyne, J.C., Gotlib, I.H., 1983. The role of cognition in depression: a critical appraisal. Psychol. Bullet. 94, 472-505.

Currie, J., Stabile, M., Manivong, P., Roos, L.L., 2010. Child health and young adult outcomes. J. Hum. Resour. 45, 517-548.

Daly, M., 2011. Intelligence differences may explain the link between childhood psychological problems and adult socioeconomic status. Proc. Natl. Acad. Sci. U. S. A. 108, E251.

Daly, M., Delaney, L., Egan, M., Baumeister, R.F., 2015. Childhood self-control and unemployment throughout the lifespan: evidence from two British cohort studies. Psychol. Sci. 26, 709-723.

Daly, M., Delaney, L., 2013. The scarring effect of unemployment throughout adulthood on psychological distress at age 50: estimates controlling for early adulthood distress and childhood psychological factors. Soc. Sci. Med. 80, 19-23.

Delaney, L., Smith, J.P., 2012. Childhood health: trends and consequences over the lifecourse. Future Child. 22, 43-63.

Eaton, W.W., Neufeld, K., Chen, L.S., Cai, G., 2000. A comparison of self-report and clinical diagnostic interviews for depression: diagnostic interview schedule and schedules for clinical assessment in neuropsychiatry in the Baltimore epidemiologic catchment area follow-up. Arch. Gen. Psychiatr. 57, 217-222.

Egan, M., Daly, M., Delaney, L., 2015. Childhood psychological distress and youth unemployment: evidence from two British cohort studies. Soc. Sci. Med. 124, 11-17.

Egan, M., Daly, M., Delaney, L., 2016. Adolescent psychological distress, unemployment, and the Great recession: evidence from the national longitudinal study of youth 1997. Soc. Sci. Med. 156, 98-105.

Egan, M., Daly, M., Delaney, L., Boyce, C., Wood, A., 2017. Adolescent conscientiousness predicts lower lifetime unemployment. J. Appl. Psychol. 102, 700-709.

Englund, P., 1999. The Swedish banking crisis: roots and consequences. Oxf. Rev. Econ. Pol. 15, 80-97.

Ettner, S.L., Frank, R.G., Kessler, R.C., 1997. The impact of psychiatric disorders on labor market outcomes. Ind. Labor Relat. Rev. 51, 64-81.

Evans-Lacko, S., Knapp, M., McCrone, P., Thornicroft, G., Mojtabai, R., 2013. The mental health consequences of the recession: economic hardship and employment of people with mental health problems in 27 European countries. PLoS One 8, e69792. https:// doi.org/10.1371/journal.pone.0069792.

Evensen, M., Lyngstad, T.H., Melkevik, O., Reneflot, A., Mykletun, A., 2017. Adolescent mental health and earnings inequalities in adulthood: evidence from the YoungHUNT Study. J. Epidemiol. Community 71, 201-206.

Fletcher, J.M., 2010. Adolescent depression and educational attainment: results using sibling fixed effects. Health Econ. 19, 855-871.

Fletcher, J.M., 2013. Adolescent depression and adult labor market outcomes. South. Econ. J. 80, 26-49.

Fryers, T., Brugha, T., 2013. Childhood determinants of adult psychiatric disorder. Clin. Pract. Epidemiol. Ment. Health 9, 1-50.

Gale, C.R., Batty, G.D., Tynelius, P., Deary, I.J., Rasmussen, F., 2010. Intelligence in early adulthood and subsequent hospitalisation and admission rates for the whole range of mental disorders: longitudinal study of 1,049,663 men. Epidemiology 21, 70-77.

Gale, C.R., Batty, G.D., Osborn, D.P., Tynelius, P., Rasmussen, F., 2014. Mental disorders across the adult life course and future coronary heart disease: evidence for general susceptibility. Circulation 129, 186-193.

Grenet, J., Hart, R.A., Roberts, J.E., 2011. Above and beyond the call. Long-term real earnings effects of British male military conscription in the post-war years. Lab. Econ. 18 (2), 194-204.

Goodman, A., Joyce, R., Smith, J.P., 2011. The long shadow cast by childhood physical and mental problems on adult life. Proc. Natl. Acad. Sci. Unit. States Am. 108, 6032-6037.

Gustavsson, A., Svensson, M., Jacobi, F., Allgulander, C., Alonso, J., Beghi, E., et al., 2011. Cost of disorders of the brain in Europe 2010. Eur. Neuropsychopharmacol. 21, $718-779$.

Hakulinen, C., Elovainio, M., Pulkki-Råback, L., Virtanen, M., Kivimäki, M., Jokela, M., 2015. Personality and depressive symptoms: individual participant meta-analysis of 10 cohort studies. Depress. Anxiety 32, 461-470.

Hillis, S.D., Anda, R.F., Dube, S.R., Felitti, V.J., Marchbanks, P.A., Marks, J.S., 2004. The association between adverse childhood experiences and adolescent pregnancy, longterm psychosocial consequences, and fetal death. Pediatrics 113, 320-327.

Holmlund, B., 2003. The rise and fall of Swedish unemployment. CESifo Working Paper Series No. 918; Uppsala University Economics Working Paper No. 2003:13. Available at: SSRN: https://ssrn.com/abstract $=396462$.

Hubers, F., Webbink, D., 2015. The long-term effects of military conscription on educational attainment and wages. IZA Journal of Labor Economics 4 (1), 10.

Kessler, R.C., Frank, R.G., 1997. The impact of psychiatric disorders on work loss days. Psychol. Med. 27, 861-873.

Lagerveld, S.E., Bültmann, U., Franche, R.L., Van Dijk, F.J.H., Vlasveld, M.C., Van der Feltz- Cornelis, C.M., et al., 2010. Factors associated with work participation and work functioning in depressed workers: a systematic review. J. Occup. Rehabil. 20, 275-292.

Layard, R., 2013. Mental health: the new frontier for labour economics. IZA Journal of Labor Policy 2, 1-16.

Lerner, D., Henke, R.M., 2008. What does research tell us about depression, job performance, and work productivity? J. Occup. Environ. Med. 50, 401-410.

Liu, S., Huang, J.L., Wang, M., 2014. Effectiveness of job search interventions: a metaanalytic review. Psychol. Bull. 140 (4), 1009-1041.

Lundborg, P., Nilsson, A., Rooth, D.O., 2014a. Adolescent health and adult labor market outcomes. J. Health Econ. 37, 25-40.

Lundborg, P., Nystedt, P., Rooth, D.O., 2014b. Body size, skills, and income: evidence from 150,000 teenage siblings. Demography 51, 1573-1596.

Mousteri, V., Daly, M., Delaney, L., 2018. The scarring effect of unemployment on psychological well-being across Europe. Soc. Sci. Res. 72, 146-169.

OECD, 2013. Mental Health and Work: Sweden. OECD Publishing, Paris. https://doi.org/ 10.1787/9789264188730-en.

OECD, 2015. Fit Mind, Fit Job: from Evidence to Practice in Mental Health and Work. OECD Publishing, Paris. https://doi.org/10.1787/9789264228283-en.

Paul, K.I., Moser, K., 2009. Unemployment impairs mental health: meta-analyses. J. Vocat. Behav. 74, 264-282.

Rumpf, H.J., Meyer, C., Hapke, U., John, U., 2001. Screening for mental health: validity of the MHI-5 using DSM-IV Axis I psychiatric disorders as gold standard. Psychiatr. Res. 105, 243-253.

Rüsch, N., Angermeyer, M., Corrigan, P., 2005. Mental illness stigma: concepts, consequences, and initiatives to reduce stigma. Eur. Psychiatry 20,529-539.

Skans, O.N., Edin, P.A., Holmlund, B., 2009. Wage dispersion between and within plants: Sweden 1985-2000. In: The Structure of Wages: an International Comparison. University of Chicago Press, pp. 217-260.

Smith, J.P., Smith, G.C., 2010. Long-term economic costs of psychological problems during childhood. Soc. Sci. Med. 71 (1), 110-115.

Stuckler, D., Basu, S., Suhrcke, M., Coutts, A., McKee, M., 2009. The public health effect of economic crises and alternative policy responses in Europe: an empirical analysis. Lancet 374, 315-323.

Swedish National Central Bureau of Statistics, 1982. Swedish socioeconomic classification (In Swedish) In: Reports on Statistical Coordination 1982, vol. 4 (Stockholm, Sweden).

Van de Mortel, T.F., 2008. Faking it: social desirability response bias in self-report research. Aust. J. Adv. Nurs. 25 (4), 40-48.

Wooldridge, J., 2003. Introductory Econometrics: a Modern Approach. Thomson SouthWestern, Cincinnati, OH. 